\title{
Artigo \\ Prototipagem e construção de um acoplador para óculos com comunicação bluetooth para fins de automação industrial e transmissão de dados
}

\author{
Leonardo Marques de Freitas ${ }^{[1]}$ e Idalmir de Souza Queiroz Júnior ${ }^{[2]}$ \\ [1] Universidade Federal Rural do Semi-árido; leonardo.xoop@gmail.com \\ ${ }^{[2]}$ Universidade Federal Rural do Semi-árido; idalmir@ufersa.edu.br
}

Recebido: 10/07/2019;

Aceito: 05/08/2019;

Publicado: 07/10/2019.

Resumo: Este artigo aborda a prototipagem e construção de um dispositivo que pode ser utilizado em óculos de proteção, com a finalidade de facilitar a comunicação em uma construção civil, além de ligar e desligar máquinas elétricas, mostrando qualquer tipo de informação relevante, como por exemplo, os EPI's necessários, cuidados na instalação e riscos na operação. A construção foi aliada a plataforma de prototipagem eletrônica Arduino, que através do módulo Bluetooth, garante a interação com o usuário através de um dispositivo móvel. O trabalho aborda um dispositivo que é direcionado para a área de segurança do trabalho e automação, dois fatores que atualmente no Nordeste não possuem avanços tão significativos quanto nas outras regiões, isto, se analisado os dados estatísticos disponíveis em relação aos choques elétricos. Portanto, o dispositivo foi desenvolvido para minimizar os acidentes e facilitar as operações dentro de um sistema industrial, por conseguinte, o mesmo em seu estado final apresentou boas características visuais e uma rápida interação com o usuário por meio da comunicação via Bluetooth. Mesmo com o projeto em funcionamento, ainda existe um amplo espaço para expansão, visto que, este não possui aspectos de um dispositivo móvel, dos quais uma delas é não possuir baterias internamente ligadas.

Palavras-chave: Segurança do trabalho; Gestão de Obras; Plataforma Arduino; Óculos de proteção; Bluetooth

\section{INTRODUÇÃO}

$\mathrm{A}^{1}$ guns dos principais problemas em uma construção civil e em instalações elétricas foram ocasionados pela dificuldade da comunicação, falta de conhecimentos para saber solucionar e evitar futuros problemas ocasionados pelas mais variadas condições de uma construção, além do risco referido ao contato direto com os equipamentos. De acordo com Corrêa de Brum [1], a pesquisa enfatizou os principais problemas em uma gestão de obras abordada no Rio Grande do Sul em 2015, um dos principais fatores que causaram atrasos nas obras foram a falta de comunicação entre as equipes de trabalho, além dos problemas rotineiros que proporcionam maiores custos e atrasos. $\mathrm{O}$ anuário estatístico brasileiro dos acidentes de origem elétrica da Abracopel de 2017 [2], apresentou que o número de acidentes elétricos fatais envolvendo eletricistas, técnico eletricista, pedreiros e ajudantes são alarmantes. Portanto, as pesquisas inovadoras envolvendo formas de acelerar as obras e diminuir os potenciais riscos vistos no anuário, estão cada vez mais sendo requisitadas pelas empresas. Na visão da empresa, acidentes fatais podem representar menores porcentagens de trabalhadores dispostos a se integrarem à equipe por falta de segurança no trabalho, além da questão dos custos com as indenizações. Desta maneira, uma maior segurança no campo do trabalho promovido pela inovação tecnológica pode acarretar um destaque maior no mercado, possibilitando o crescimento da empresa.

O anuário estatístico da Abracopel [2] mostrou que ocorreram 851 acidentes elétricos em 2017 no Brasil, dos quais 627 foram acidentes fatais, e destes, $46 \%$ foram na região Nordeste que carece muito de informação e tecnologia. Mesmo não sendo a região mais populosa, a região Nordeste corresponde a quase $50 \%$ de todos 
os acidentes fatais deste ano, este problema engloba várias vertentes, contudo, algumas delas podem ser reduzidas através da informação e tecnologia no trabalho, já que, um dos enfoques é reduzir os riscos relativos a falta de informação no manuseio de máquinas elétricas.

Identificando a carência da tecnologia no campo do trabalho, o presente estudo se propõe a desenvolver um protótipo que pode ser acoplado nos óculos de proteção, conhecidos como EPI (Equipamento de Proteção Individual), para realizar a comunicação Bluetooth com o aparelho celular. A conexão possibilitará possíveis transmissões de informações em mensagens de texto, além de ligar e desligar as máquinas elétricas, no qual cada um dos recursos do protótipo são colocados com objetivos distintos. A transmissão das informações é destinada a comunicação entre as equipes nas obras, sabe-se que, em grandes construtoras, as equipes dependem umas das outras para realizar serviços distintos, e nem sempre os aparelhos celulares podem serem utilizados rotineiramente, por motivo de distrações ou até mesmo, redução de produtividade dos operários e técnicos.

O objetivo do trabalho é projetar em um óculos de proteção informações essenciais no formato de texto para os técnicos e ou responsáveis da equipe poderem se comunicar entre si, proporcionando maiores produções sem grandes interrupções. Como também, o recurso de ligar e desligar máquinas elétricas tem como finalidade a automação e ampliação do preparo dos funcionários da empresa. Assim, o protótipo contribuirá, possibilitando que o funcionário possa ligar ou desligar as máquinas elétricas à distância, além de, receber as informações essenciais sobre como proceder em situações adversas no ligar da máquina. Este funcionamento contribuirá com a gestão do funcionamento, pois algumas empresas contam apenas com um funcionário para o ligamento de diversas máquinas, porém, cada máquina possui seus cuidados específicos, afinal, foram produzidas por fabricantes distintos. Portanto, ao ligamento de cada máquina o funcionário fica obrigado a reler os cuidados fundamentais de cada antes da mesma ser ligada, deste modo, utilizando o equipamento proposto, ele poderá acessar as informações detalhadamente antes o ligamento da máquina. Os principais objetivos pretendidos na elaboração deste trabalho é a criação de um protótipo operacional e um aplicativo de celular que consiga integrar todos os recursos necessários a este protótipo.

\section{REFERENCIAL TEÓRICO}

\subsection{Plataforma Arduino}

De acordo com o site oficial do Arduino [3], o mesmo é uma plataforma eletrônica de código aberto baseada em hardware e software fáceis de usar. A Figura 1 mostra a plataforma Arduino Uno, que é bastante conhecida por ser o cérebro de diversos projetos eletrônicos, pois, conta com uma interface entre o computador para que possa ser programada, tornando o trabalho de construir dispositivos eletrônicos mais fácil. O Arduino é constituído de entradas e saídas, digitais e analógicas, das quais tem a função de captar e enviar informações. Ao contrário do que muitos pensam, o Arduino em si é somente um microcontrolador (um chip), que conta com diversos componentes eletrônicos lógicos que garantem a funcionalidade de suas entradas digitais. Além disto, existe uma diferença do Arduino para com outros dispositivos, é que, a mesma consegue captar um sinal analógico e transformá-lo em um sinal digital e vice-versa. Um sinal digital tem o funcionamento de acordo com os princípios booleanos, ou seja possuem dois estados, o verdadeiro ou o falso, e pode ser também associado ao modelo binário 1 e 0 , assim, ou o Arduino envia o sinal ou não envia, ele não consegue analisar um sinal que está no seu meio termo [4]. Um exemplo bem claro é a temperatura, os termistores são resistores que variam com a temperatura no qual ele se encontra [5]; este dispositivo é um dos mais comumente utilizados no Arduino; portanto, caso o Arduino possuísse apenas portas digitais, a temperatura que o mesmo iria receber seria sempre, a mínima ou a máxima, ou seja, caso a temperatura ambiente fosse de 30 graus, o Arduino iria receber um sinal verdadeiro e iria retornar para o programador o máximo valor possível, sendo assim, muito distante do real. Com as portas analógicas o Arduino pode receber e interpretar sinais de tensão variando entre 0 e $5 \mathrm{~V}$, e assim ao transformar para digital retorna valores condizentes com a realidade. A plataforma Arduino em si é toda a placa de circuito com os componentes, no qual tem a finalidade de facilitar a alimentação, a interface com o computador e o acesso as portas, além de dispor de alguns dispositivos de proteção que garante que o chip não seja danificado. Por ser uma plataforma open-source, o mesmo pode ser modificado de acordo com a necessidade dos projetos. Portanto, por este projeto ter a necessidade de ser o mais compacto o possível, foi necessário utilizar Arduino Nano (Figura 2), ao invés de utilizar o Arduino Uno que foi exemplificado na Figura 1. O Arduino Nano conta com quase todos recursos que o Arduino Uno, a diferença em maior 
particularidade é relativo a facilidade de conexão dos fios, pois, o Arduino Uno possui uma fácil inserção dos componentes, sem a necessidade de soldagem. Em contrapartida, o Arduino Nano é muito mais compacto que o Uno, sendo possível de integrar ao protótipo desenvolvido.

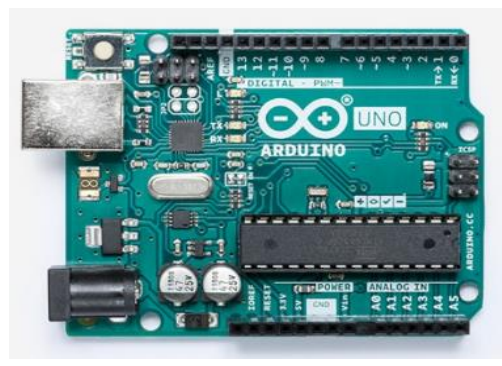

FIGURA 1. Plataforma Arduino Uno R3. (Arduino.cc)

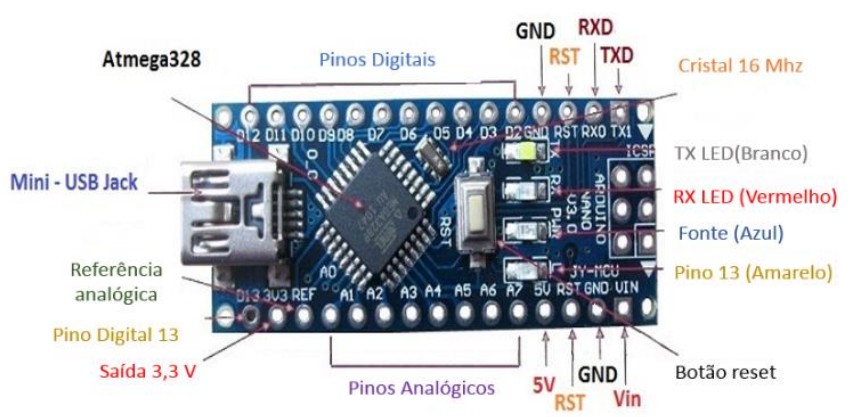

FIGURA 2. Plataforma Arduino Nano. (Adaptada - THE ENGINEERING PROJECTS)

\subsection{Módulo bluetooth hc-06 (comunicação)}

A necessidade de comunicação do Arduino com um smartphone poderia ter sido feita através de comunicação por Wi-Fi, por rádio frequência, por Bluetooth, dentre outros, contudo, para este projeto a forma de comunicação escolhida foi através da tecnologia Bluetooth, principalmente pela sua facilidade de conexão, custo e rápida troca de informações, reduzindo o máximo de erros possíveis que poderiam prejudicar o andamento de uma obra. A principal deficiência desta tecnologia é o fato de não conseguir alcançar uma área muito extensa. De acordo com Siqueira [7], Bluetooth é um padrão de comunicação sem fio de curto alcance, baixo custo e baixo consumo de energia que utiliza tecnologia de rádio e possibilita uma conexão com uma distância máxima de 100 metros, variando alguma das suas características de acordo com o dispositivo. Em relação ao dispositivo HC-06 disposto na Figura 3, o seu datasheet disponível pela companhia Guangzhou HC Information Technology [8] mostra que o dispositivo é um transceptor sem fio, que possui sensibilidade (taxa de erro de bit) até $-80 \mathrm{dBm}$ e um intervalo de alteração de saída entre -4 e $+6 \mathrm{dBm}$. Para este projeto as características fundamentais na confecção podem ser elencadas conforme a Figura 3.

- $\quad$ Possui Módulo EDR e o intervalo de mudança de profundidade de modulação: 2 Mbps - 3 Mbps;

- Possui uma antena embutida de 2,4 GHz;

- $\quad$ Tem FLASH externo de $8 \mathrm{Mb}$;

- $\quad$ Trabalha em baixa tensão $(3,1 \mathrm{~V} \sim 4,2 \mathrm{~V})$ e corrente de emparelhamento de $(30 \sim 40 \mathrm{~mA})$;

- $\quad$ Corrente de comunicação de $8 \mathrm{~mA}$;

- $\quad$ Protocolo USB compatível com 2.0;

- $\quad$ Transceptor digital sem fio de $2,4 \mathrm{GHz}$;

- $\quad$ Dimensões (27 mm x $13 \mathrm{~mm}$ x $2 \mathrm{~mm})$;

- Qualquer interferência de onda de 2.4 MHz, tem a capacidade de emitir $3 \mathrm{dBm}$; 
- Temperatura de trabalho de $-25^{\circ} \mathrm{C}$ até $75^{\circ} \mathrm{C}$.

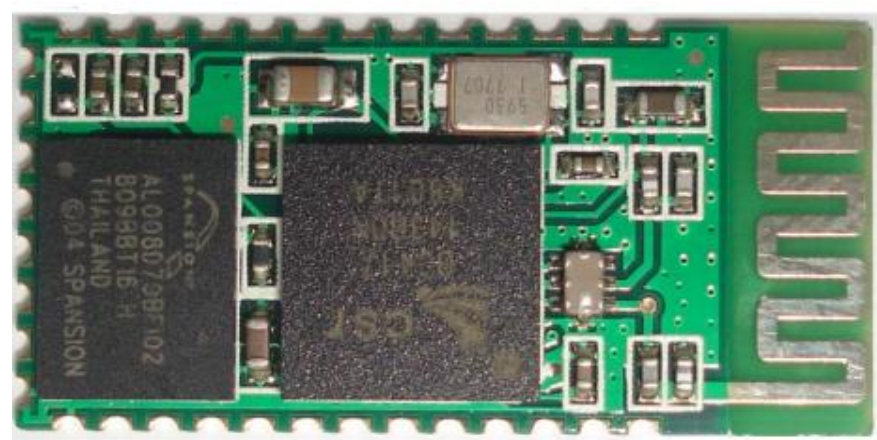

FIGURA 3. Módulo Bluetooth HC-06 (Guangzhou HC Information Technology)

\subsection{Display OLED Adafruit}

Um dos dispositivos mais importantes é um módulo display (Figura 4), que tem o objetivo de garantir a interação do operador com o aparelho eletrônico para mostrar em mensagem de texto se os recursos estão sendo realizados ou não. O fabricante escolhido foi a empresa Adafruit, por ser uma das empresas que mais se destacam na produção de módulos display nas mais variadas formas, no qual caracteriza este módulo como [9] monitores pequenos com cerca de uma polegada na diagonal, são muito legíveis por razão do alto contraste feito de pixels OLED (Diodo emissor de luz orgânico) brancos e individuais de 128 x 64, no qual cada um pode ser ligado ou desligado utilizando um chip controlador, além de possuir baixa potência e alta nitidez. O microcontrolador necessário para enviar mensagens de texto e gráficos deve ter mais de 1k de memória RAM (Memória de acesso aleatório) por razão do monitor estar em buffer (memoria temporária), tal microcontrolador para este protótipo será o próprio ATmega328 (presente no Arduino uno e nano) e tem a capacidade de se comunicar com este dispositivo. A necessidade da tecnologia OLED surgiu pela necessidade de obter um equipamento mais compacto possível, além da necessidade de explorar a alta nitidez descrita pelo fabricante.

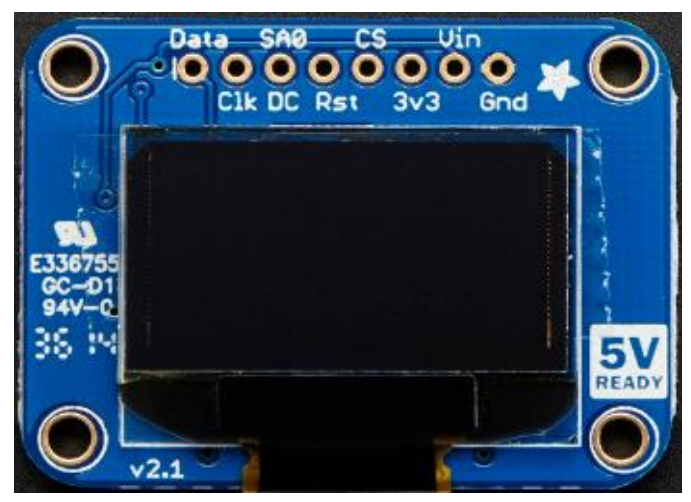

FIGURA 4. Display OLED Adafruit. (ADAFRUIT)

\subsection{Módulo relé 5v}

Os módulos relés de contato são dispositivos que acionam cargas através de microcontroladores Arduino/PIC/8051 [10]. Tal acionamento ocorre através de um sinal lógico de $5 \mathrm{~V}$ e possui saídas com opções Normalmente Aberto (NO) e Normalmente Fechado (NC). O módulo pode acionar cargas de até 5500 Watts sendo corrente contínua ou alternada com total segurança para o microcontrolador, no qual é protegido por opto acopladores que conseguem proteger o dispositivo contra surtos de até 5000 V. O módulo relé será responsável pelo acionamento das máquinas elétricas através de um sinal de $5 \mathrm{~V}$ fornecido pelo Arduino para cada máquina separada. As principais características do módulo relé (Figura 5) podem ser descritas por:

- Saídas com opção Normalmente Aberto (NO) e Normalmente Fechado (NC); 
- Saída de $5500 \mathrm{~W}$ por contato;

- Duas formas de alimentação: através do Arduino ou com fonte de alimentação externa.

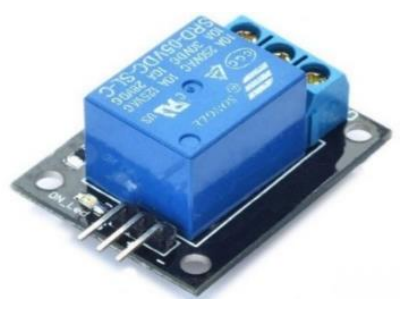

FIGURA 5. Módulo Relé. (Flipeflop)

\subsection{TP4056 módulo de carregamento}

O módulo TP4056 consiste em um módulo de carregamento de baterias de lítio (Figura 6), com a finalidade de fornecer energia para os equipamentos e facilitar o carregamento da bateria acoplada. As características principais deste dispositivo elencadas pelo fabricante EK.T. [11] são:

- Corrente de $1^{a}$ ajustável;

- Precisão de carregamento de $1,5 \%$;

- Tensão de entrada de 4,5 V até 5,5 V;

- Tensão máxima de carregamento 4,2 V;

- LED indicativo de carregamento e de carregamento máximo;

- Dimensões $(2,6 \mathrm{~cm}$ x $1,9 \mathrm{~cm}$ x 1,0 cm).

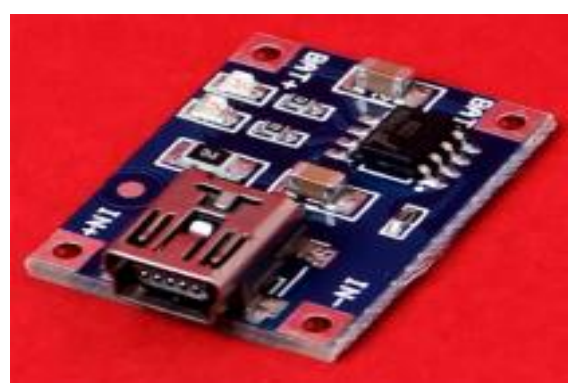

FIGURA 6. TP4056 Módulo de carregamento. (Datasheet EK.T)

Sendo assim, os componentes utilizados neste trabalho podem ser descritos por Arduino Nano, módulo Bluetooth HC-06, display OLED 0.92" monochrome, módulo Relé, TP4056, smartphone, placa espelhada, lente, bateria de Lipo 3.7 V 800 mAh e uma peça de acrílico.

\section{METODOLOGIA DO MODELO PROJETADO}

\subsection{Apresentação geral}

O modelo consiste na implementação de duas funções, que consistem em uma comunicação entre acopladores (Serial) e o controle de máquinas elétricas. A Figura 7 mostra a primeira função que consiste numa comunicação entre os acopladores, no qual, qualquer acoplador pode enviar informações para qualquer outro acoplador. A Figura 8 consiste no controle de qualquer máquina em uma determinada indústria, utilizando outro Arduino e relés. 


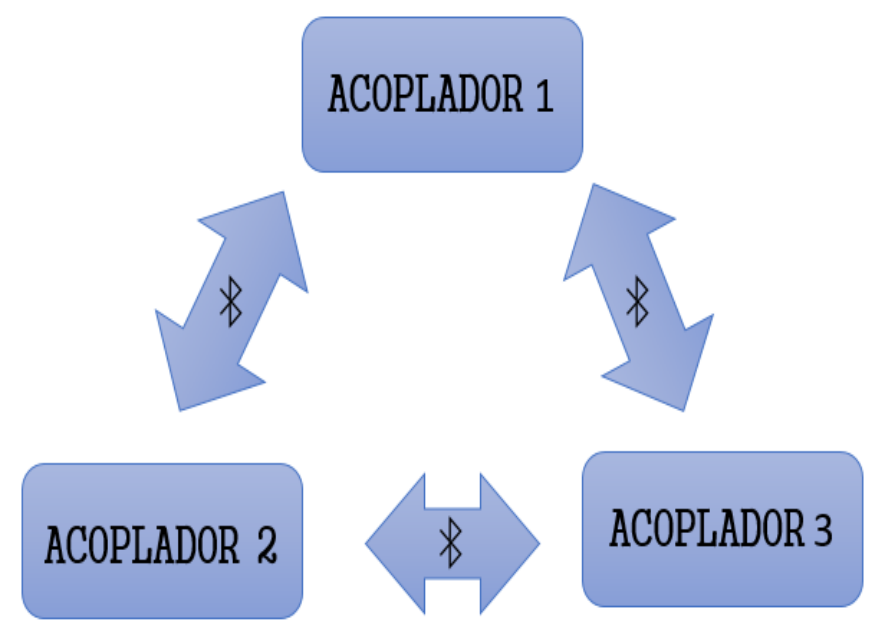

FIGURA 7. Comunicação entre acopladores (Serial). (Autoria própria)

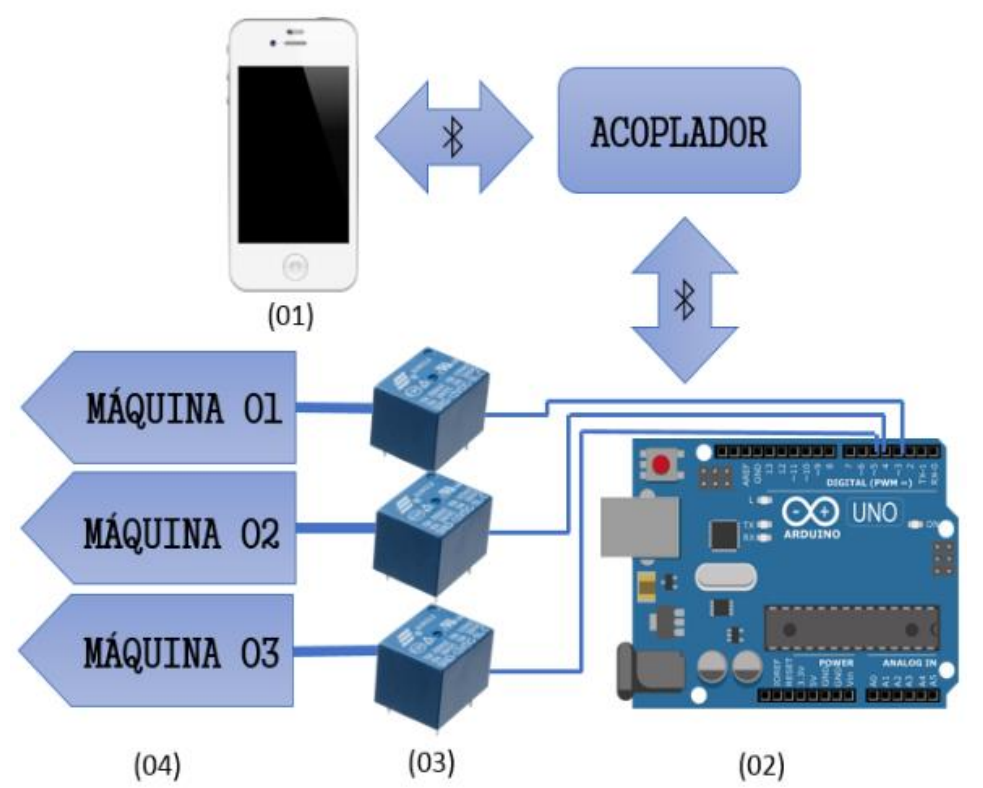

FIGURA 8. Controle de máquinas elétricas. (01, 02, 03 - [12]; Autoria própria)

\subsection{Aplicativo $s \&$ f buildings}

O aplicativo S\&F BUILDINGS (Smart and Fast Buildings) tem a função de facilitar a interação do operador para com o acoplador modelo. No aplicativo, encontra-se todas as funções disponíveis pelo equipamento, elaboradas e organizadas de forma mais simples o possível. Na Figura 9, tem-se o símbolo do aplicativo e a sua interface inicial, no qual o botão de comunicação serial e de controle de máquinas devem ser pressionados para serem empregados da forma desejada. $\mathrm{O}$ aplicativo foi realizado utilizando uma interface online disponível pelo MIT (Massachusetts Institute of Technology) conhecido como AppInventor [13], no qual tem o objetivo de facilitar a programação direcionada para dispositivos Android e IOS através de codificação em blocos. 

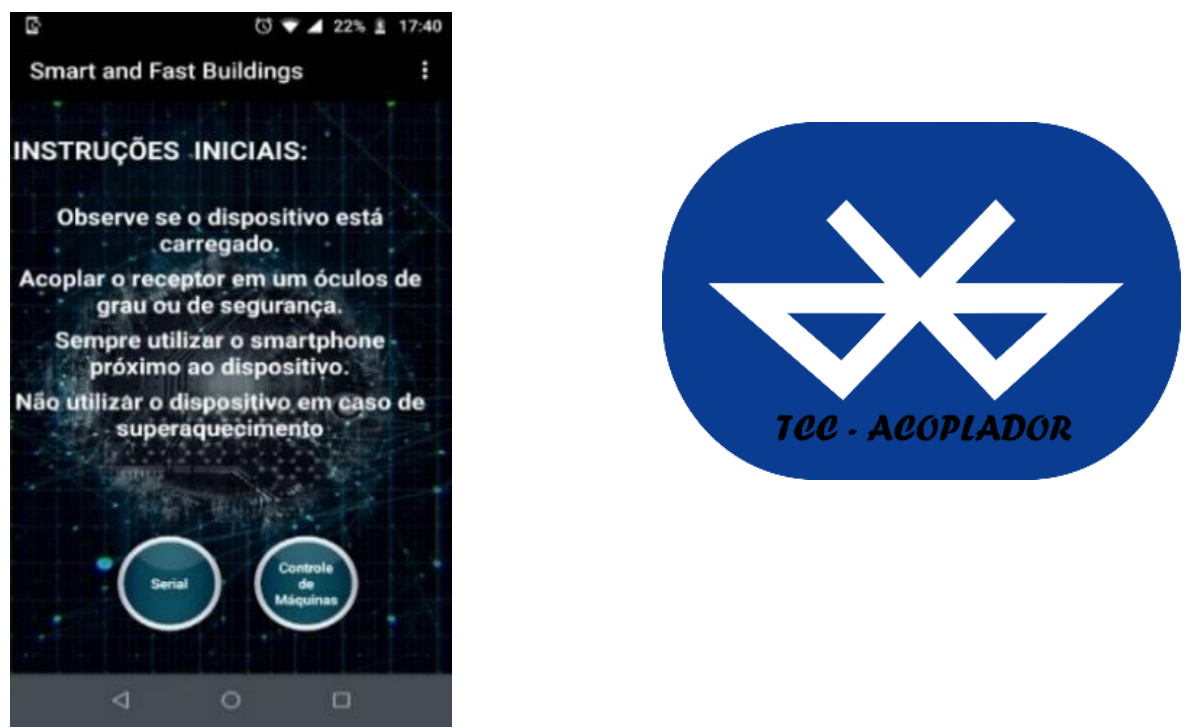

FIGURA 9. Interface inicial do aplicativo e símbolo. (Interface inicial - Autoria própria; Símbolo do aplicativo - Adaptada - PIXABAY)

\subsubsection{Controle de máquinas}

Nesta seção do aplicativo se torna possível controlar máquinas elétricas remotamente através de um celular e com as informações essenciais e necessárias para operar da máquina. As mensagens irão aparecer no visor dos óculos, como por exemplo: os EPI's necessários, cuidados na instalação, danos causados a desobediência das regras, e dentre outras. Na Figura 10 (a), é possível perceber como está organizado a seção do aplicativo, no qual o botão em azul se refere a uma máquina desligada, e ao ser acionada uma máquina um botão em vermelho indicará que a máquina se encontra em operação.

\subsubsection{Comunicação serial}

Nesta seção do aplicativo é possível enviar informações para o visor dos óculos, qualquer informação digitada na aba de comunicação será impressa no visor dos óculos assim que for acionado o botão Enviar, que se encontra logo acima da caixa de texto (Figura $10 \mathrm{~b}$ ).

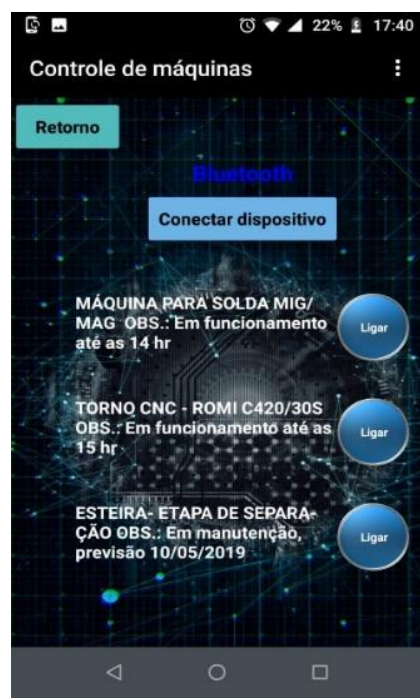

(a)

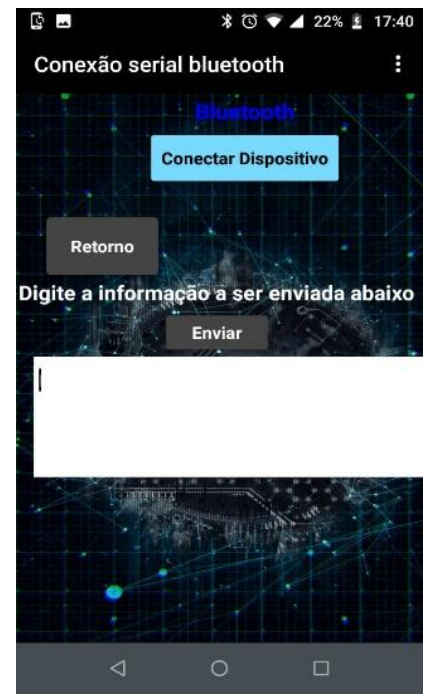

(b)

FIGURA 10. (a) Controle de máquinas e (b) Conexão serial. (Autoria própria) 


\section{DESENVOLVIMENTO DO PROTÓTIPO}

A prototipagem foi realizada de modo a atender os requisitos deste projeto. A Figura 11, mostra o esquema desenvolvido, que se utiliza de um módulo HC-06, representado na Figura 11 como 02, que tem a finalidade de conectar o dispositivo com o Smartphone, no intuito de receber as informações do mesmo e enviar tais informações ao Arduino. É fundamental perceber que o módulo Bluetooth precisa de dois resistores no pino RXD, que tem a função de divisor de tensão (a tensão de alimentação $5 \mathrm{~V}$ do Arduino será dividida entre os dois resistores), com o intuito de proteger o módulo, pois seu canal RXD de comunicação só pode receber uma tensão máxima de 3,3 V. O componente mostrado na Figura 11 como 04, é a plataforma Arduino Nano, que possui um microprocessador programável através de sua porta micro USB embutida na placa, ele que controlará os dados fornecidos pelo programador. Além deste, o dispositivo representado por 03 é o módulo display, que é responsável pela imagem no visor da tela.

As máquinas elétricas, representadas por M1, M2 e M3 neste trabalho serão ligadas através dos módulos relés (05). Tais módulos, possuem dois estados, conhecidos como NO (normalmente aberto) e NC (normalmente fechado). Caso o Arduino não forneça um sinal de tensão, o módulo ficará na posição NC, caso o contrário, ficará em NO, ou seja, quando o Arduino receber alguma informação do módulo Bluetooth, ele poderá, dependendo dos dados recebidos, enviar um sinal de tensão para o módulo relé, que acionará o mesmo para a posição NO, no qual terá uma máquina ligada em uma fonte de tensão alternada, que no caso da Figura 11 está representada como (01).

Analisando a Figura 11 e 12 é possível perceber que não existe módulo de carga, nem baterias que deixariam o projeto de acoplador portátil. Pois, a intenção foi deixar o projeto pronto para a utilização em indústria ou de forma residencial com a colocação de um módulo TP4056 e baterias, onde este módulo funcionaria de forma simples no conectar do dispositivo ao Arduino, além de possibilitar o carregamento das baterias. Destacamos, que estes procedimentos não foram realizados pois o enfoque deste projeto não seria deixar o acoplador pronto para uso, portátil e versátil, mas, como dispositivo que possa realizar todas as funções abordadas neste trabalho desenvolvido.
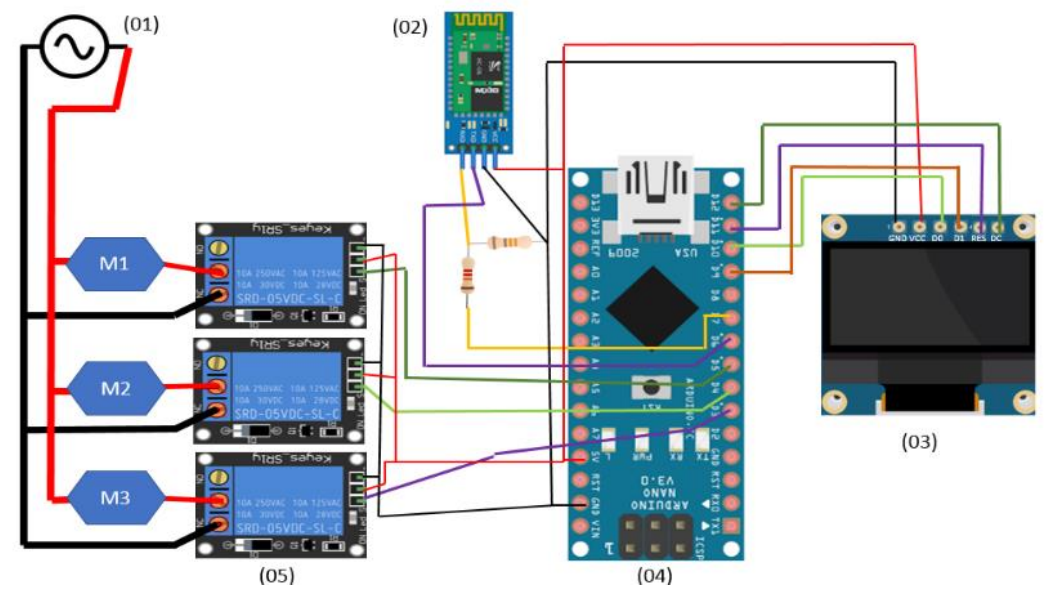

(03)

FIGURA 11. Esquema eletrônico realizado (01 - [14]; 04 - [15]; Resistores - [16], [20]; Autoria própria)

A Figura 12, representa o controle utilizando dois módulos Bluetooth (03), que fazem conexão entre si, e o Arduino Uno (02), quando este receber o sinal desejado do acoplador que ligará uma máquina determinada pelo projetista. Esta figura representa a forma que deveria ter sido projetado o acoplador, porém, por motivos de falta de materiais, o protótipo realizado teve que ser totalmente embutido em um único microcontrolador. 


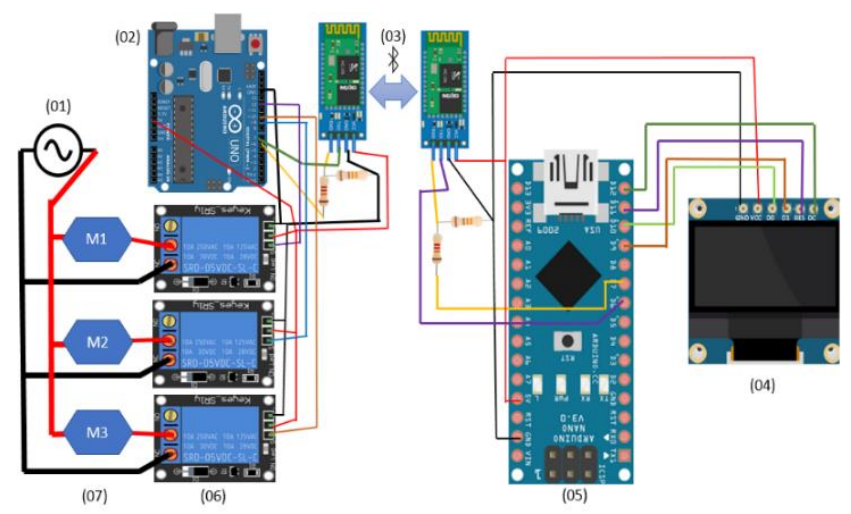

FIGURA 12. Esquema eletrônico ideal (01 - [14]; 02 - [12]; 05 - [15]; Resistores - [16], [20]; Autoria própria)

Após realizado o projeto eletrônico do acoplador foi feito um protótipo utilizando plástico comercial, mais especificamente foi reaproveitada a carcaça de uma fonte para notebook e assim, foi projetado o acoplador na forma que fosse possível a integração de todos estes componentes dentro do mesmo. Através do software Inventor da Autodesk, foi projetado o primeiro protótipo para este trabalho, que pode ser visto na Figura 13. A imagem será impressa no visor (01), através do módulo display (02) e da lente, que será responsável pela ampliação da imagem a ser projetada no visor dos óculos. O Arduino Nano (04) e o módulo Bluetooth (03) serão encaixados no dispositivo de forma que mais fácil a passagem da fiação no momento da montagem.

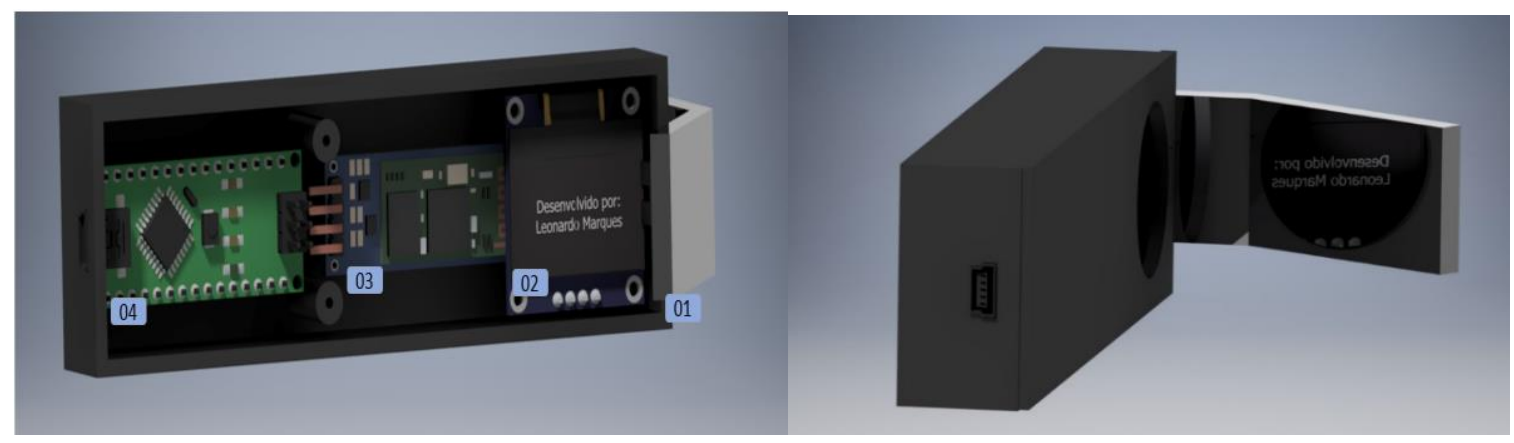

FIGURA 13. Primeiro protótipo do acoplador. (02 - [18]; 03 - [19]; 04 - [20]; Autoria própria)

Após a prototipagem, a construção se tornou mais simples já que as dimensões já foram previamente testadas para garantir que os dispositivos se encaixarão no acoplador. A construção do primeiro protótipo é representada pela Figura 14 que obedeceu a todas as especificações necessárias e imprimiu a mensagem no visor, porém, foi constatado que a imagem estava invertida, pois, é o reflexo da imagem disponibilizada pelo display OLED. Como forma de ajustar a imagem foi utilizado um simples espelho que tem a função de inverter a imagem em primeira instância e, após isto, a imagem será invertida novamente pois o reflexo da imagem invertida representará a imagem real.

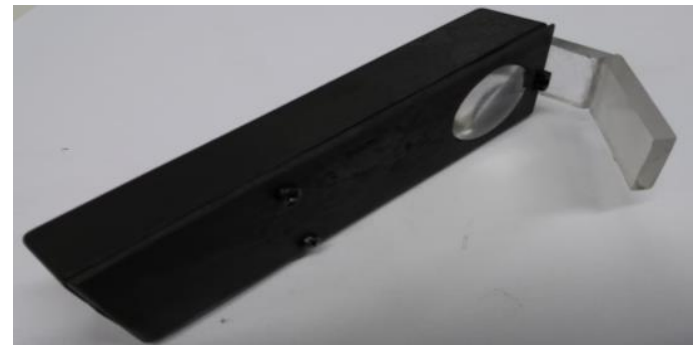

FIGURA 14. Primeiro protótipo do acoplador construído. (Autoria própria) 
Contudo, este ajuste não pode ser realizado no protótipo disponibilizado na Figura 14, já que, não há espaço suficiente para a inclusão de um espelho no acoplador. Portanto, foi projetado um novo protótipo que possui o mesmo circuito descrito na Figura 11, porém, é um pouco maior que o anterior, pois, deve primeiramente refletir a imagem em um espelho. O protótipo destacado na Figura 15 também foi realizado no software Inventor e possui tal qual o protótipo anterior, o módulo display, o Arduino Nano e o módulo Bluetooth, possui no seu projeto um espelho (05) e um prisma (06). O prisma utilizado foi do tipo retangular ou do ângulo direito (Figura 17) que tem a função da lente e a parte onde será projetada a imagem, pois, reflete as informações em noventa graus, além disto, tem a função de melhorar a imagem refletida, já que os raios externos não influenciarão na imagem tanto quanto no primeiro protótipo. O protótipo destacado na Figura 15 teve como base o projeto realizado por Alain Mauer [21], que criou um protótipo acoplador para óculos voltado para uma conexão direta com multímetros em testes de força nos quadros de distribuição.

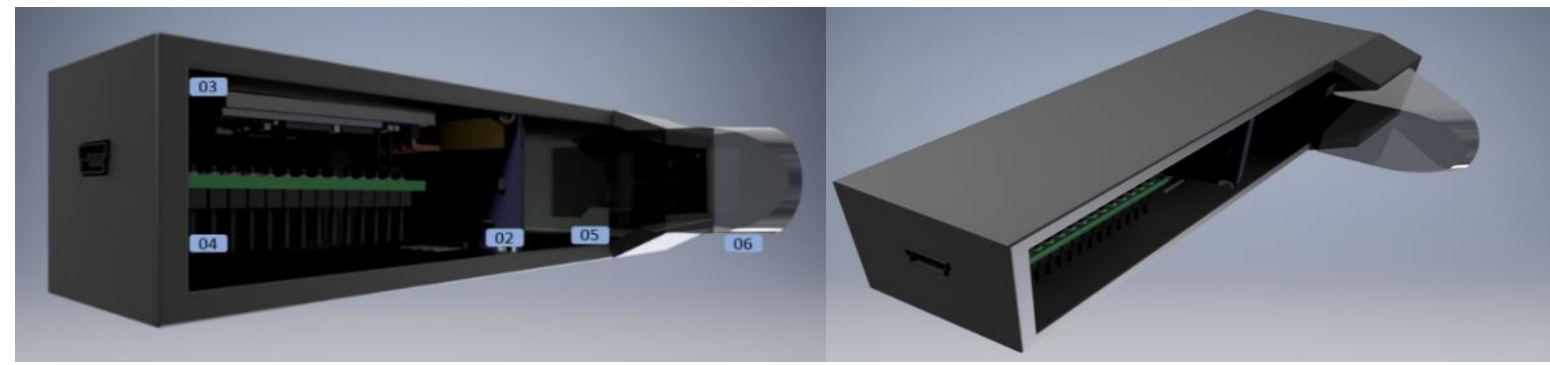

FIGURA 15. Protótipo do acoplador em seu estado final. (02 - [18]; 03 - [19]; 04 - [20]; Autoria própria)

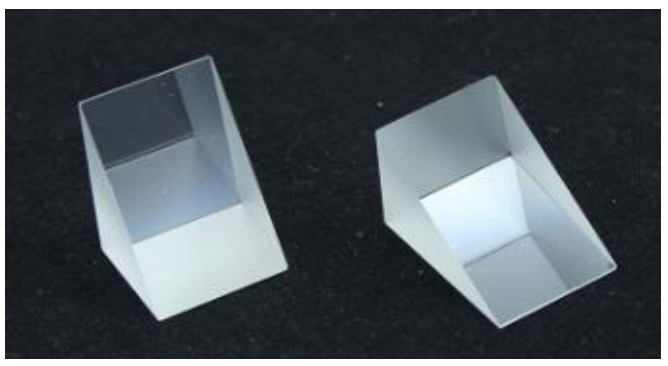

FIGURA 16. Prisma 90 graus de ângulo direito. (ALIBABA)

O processo de construção do protótipo atualizado teve como material, um plástico convencional (tal qual o material da primeira construção). Além disto, foi necessário o corte de uma peça de espelho com dimensões de $27 \mathrm{~mm}$ x $21 \mathrm{~mm}$ efetuado através de um cortador de vidro, que garantiu a precisão no corte. O espelho foi posicionado próximo aos 45 graus, de forma a refletir a imagem disponibilizada pelo display para a parte superior (externamente ao acoplador), e em seguida posicionado o prisma de forma a superfície maior em oposição ao sujeito que estará visualizando o prisma, como na Figura 15. O resultado final foi o disposto na Figura 17, que consiste em um acoplador para óculos funcional, com algumas falhas mecânicas por consequência de reutilizar um plástico que teve que se adequar ao projeto proposto.

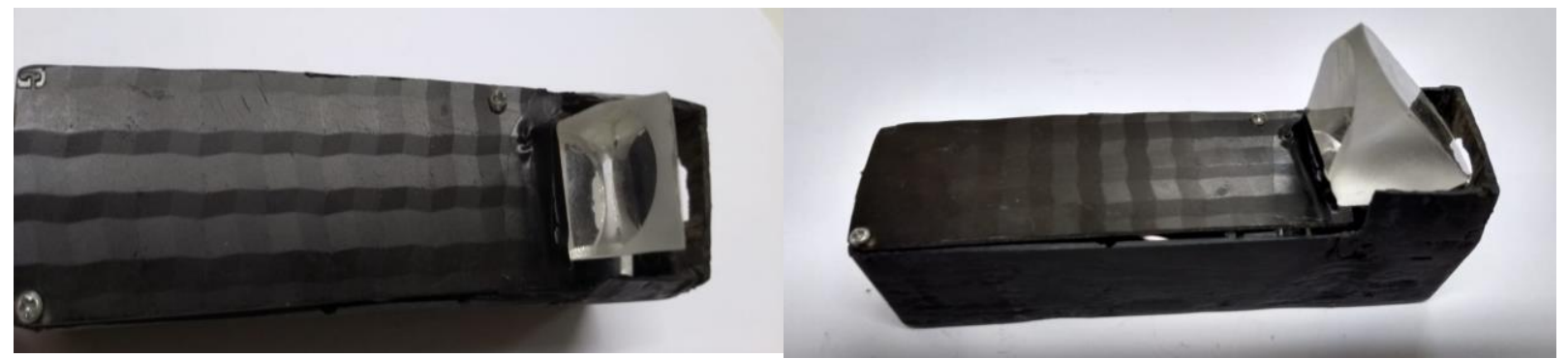

FIGURA 17. Protótipo final do acoplador construído. (Autoria própria) 


\subsection{Aplicação do modelo proposto}

O projeto foi testado nas suas duas funcionalidades, relacionado ao controle de máquinas e a comunicação serial. Em cada uma, foi analisado o desempenho do protótipo, quanto a sua velocidade de resposta, facilidade de leitura dos dados projetados e em uso.

Para a função de controle das máquinas foi feito um suporte utilizando luminárias simples, lâmpadas de uso doméstico. As lâmpadas representam as máquinas elétricas dispostas no aplicativo que ao serem ligadas representam que a máquina elétrica referente foi ligada, e para a função desligar, quando a ação for contrária, sem luz. A aplicação pode ser analisada na Figura 18 e 19, no qual, está montada referente ao circuito da Figura 11. Não foi possível tirar a foto da informação por completo, pois a impressão na tela referentes poderá ser visualizada a olho humano, junto ao protótipo. A Tabela 1 mostra os resultados gerais da aplicação deste projeto.

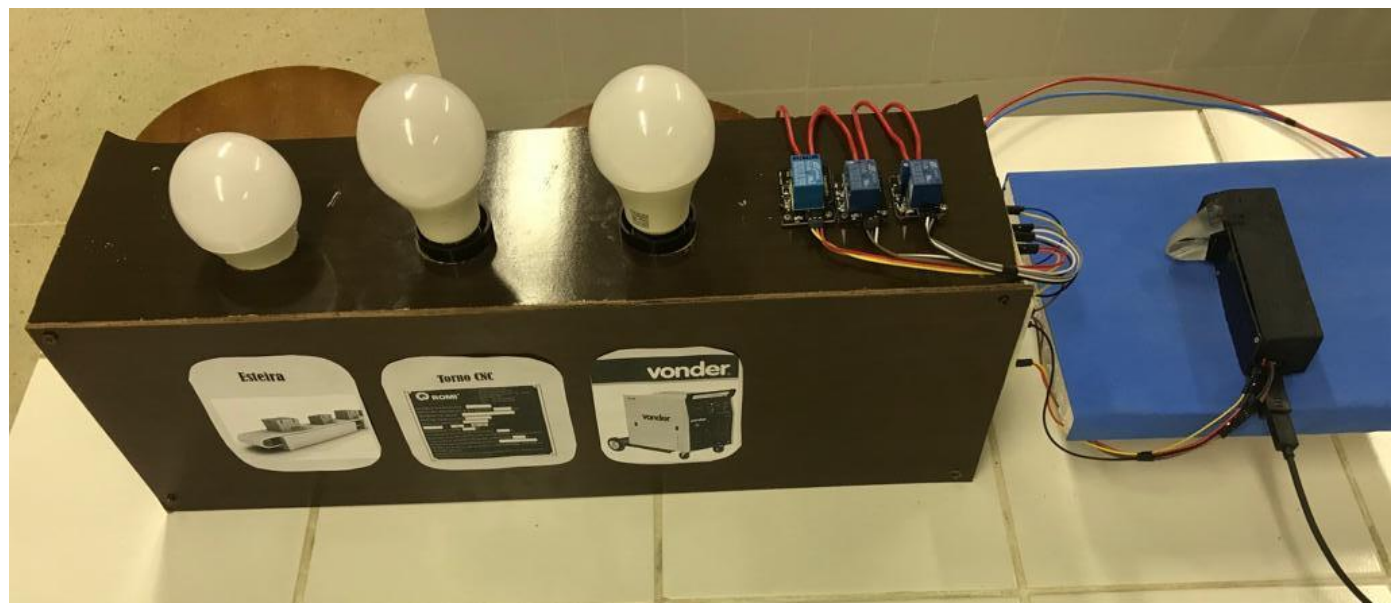

FIGURA 18. Suporte completo para teste de controle de máquinas com acoplador. (Autoria própria)

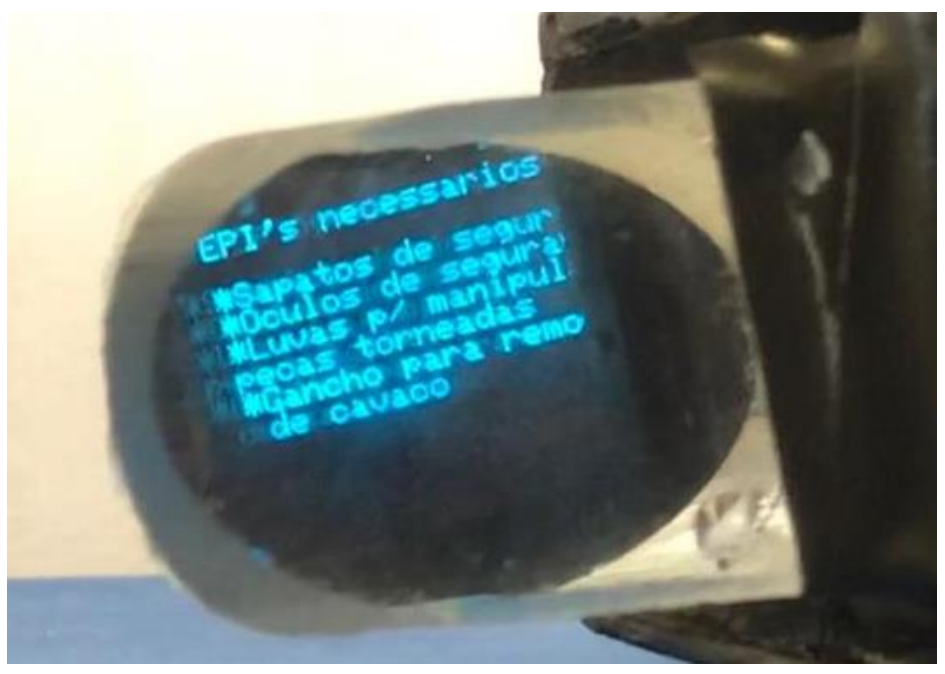

FIGURA 19. Acoplador mostrando as informações das máquinas elétricas. (Autoria própria)

A função comunicação serial (Figura 20) foi testada e analisada quanto as informações que não foram possíveis de serem impressas no protótipo. O resultado desta função se encontra na Tabela 1, quanto aos seus pontos positivos e negativos. 

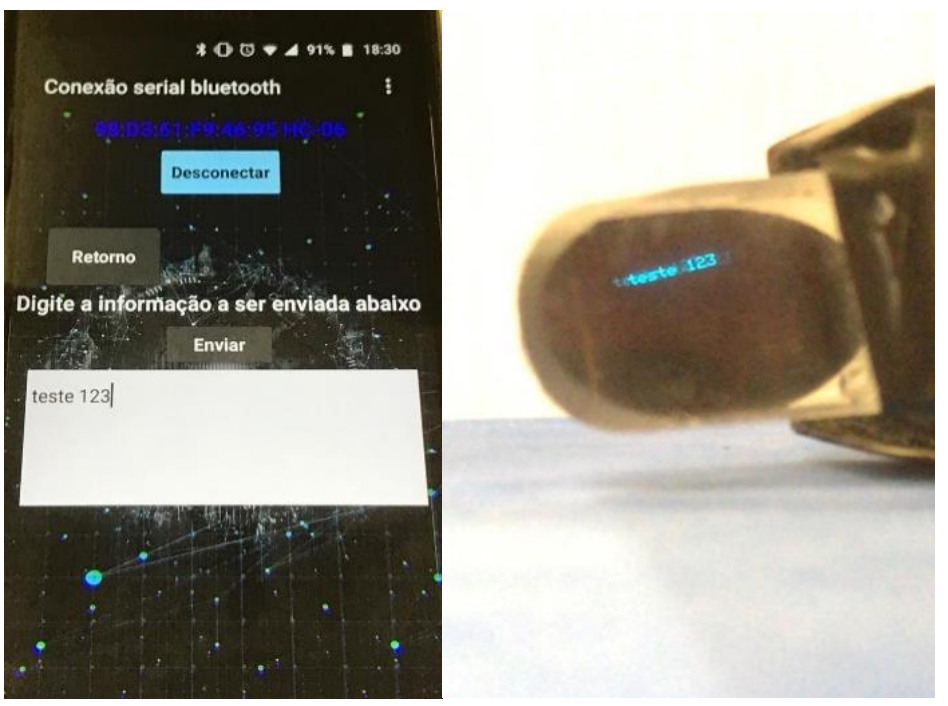

FIGURA 20. Teste de comunicação serial (Autoria própria).

Tabela 1. Vantagens e desvantagens das funções do acoplador. (Autoria própria)

\begin{tabular}{ccc}
\hline Função & Vantagens & Desvantagens \\
\hline Controle de máquinas & Resposta rápida, atualização & Não possui acionamento \\
& rápida das máquinas & mecânico e visualização \\
& ligadas no aplicativo e de & nos óculos um pouco \\
& fácil interação. & embaçada. \\
\hline Comunicação Serial & Informação rapidamente & Não aceita qualquer tipo de \\
& enviada e projetada no & acento. \\
& acoplador. & \\
\hline
\end{tabular}

\section{CONCLUSÃO}

A posição preocupante do Estado do Rio Grande do Norte nos índices disponibilizados pela Abracopel mostra o quanto é importante o desenvolvimento de projetos que ajudem a diminuir os riscos rotineiros dos funcionários das empresas de construção civil e em instalações elétricas. Portanto, este projeto apresenta um dispositivo e um aplicativo para atender a esta demanda. O protótipo possui uma ampla potencialidade para ampliação e melhoria, além de ser um produto com custos reduzidos, se for levado em conta todos os outros equipamentos de proteção que são necessários para uso do funcionário, e ainda se levarmos em conta os Smart Glasses, o custo será ainda mais reduzido, visto que, mesmo que estes não possuam as mesmas finalidades foram analisados neste trabalho por também possuírem potencial para serem utilizados neste escopo do acoplador de óculos descrito neste trabalho de conclusão de curso.

A plataforma Arduino foi uma das principais ferramentas utilizadas por ser de fácil manipulação e ainda, por possuir diversas plataformas que podem ser destinadas para cada tipo de projeto. O Arduino Nano foi o mais indicado por ser um dispositivo compacto e versátil. Além deste, os softwares Inventor da Autodesk e o App Inventor do MIT, proporcionaram um maior detalhamento no projeto. O software da Autodesk diminuiu os erros na construção o software da MIT proporcionou uma maior interação do operador com o dispositivo. Mesmo com alguns pontos negativos, como o fato de não aceitar a acentuação, proporcionando um desconforto visual, outro ponto, é não ser tão compacto o quanto deveria. O dispositivo mostrou ter bastante velocidade de interação com o usuário, além de possuir ferramentas que podem serem aprimoradas e integradas em um sistema real de automação industrial. 
Como apresentado, o protótipo construído não está pronto para ser utilizado em uma situação real. Para que isto seja possível, continuaremos o estudo analisando o dispositivo no seu estado final (protótipo), primeiramente se tornam necessários a inclusão de baterias e do módulo de carregamento, além disto, para os projetos futuros se torna essencial a criação de uma placa de circuito impresso internamente ao dispositivo, diminuindo o espaço da passagem dos fios, como também o peso do dispositivo, bem como, a utilização de uma plataforma mais compacta ainda, como é o caso de Arduino pro mini, ou semelhante, que podem serem soldados em uma placa de circuito impresso, ou também pode ser analisado utilizando somente os componentes essenciais de um Arduino uno, pois a plataforma possui diversos componentes que não são aplicados. É importante destacar também a compactação com a utilização do módulo display menor, como o de 0,66 polegadas, já disponível no mercado.

Mesmo com todos os detalhes, o estudo referente a este dispositivo se mostrou bastante proveitoso, visto que, foi abordado neste projeto alguns softwares, estudo óptico, construção mecânica, desenvolvimento eletrônico e programação, além da criação de um aplicativo totalmente operacional. Portanto, foram estudadas e apresentadas diversas vertentes que proporcionaram uma interdisciplinaridade, área atualmente discutida como base para a construção de qualquer tipo de inovação tecnológica, pois, envolver conhecimentos em diversas áreas para uma aplicação prática decorrente de um problema ordinário, é uma ferramenta propulsora para o desenvolvimento de qualquer solução, principalmente se tratando da engenharia.

\section{REFERÊNCIAS}

[1] DE BRUM, THAMILA CORRÊA. Avaliação crítica dos principais problemas de gestão de obras no Rio Grande do Sul: 2015. Universidade Federal de Santa Maria. Rio Grande do Sul.

[2] ABRACOPEL. Anuário Estatístico Abracopel de Acidentes de Origem Elétrica 2018. Disponível em: <http://a7d4083.contato.site/confirmado-anuario2018/>. Acesso em: 2 novembro 2018.

[3] HOME PAGE, ARDUINO. What is Arduino? Disponível em: 〈https://www.arduino.cc〉. Acesso em 26 janeiro 2019.

[4] FIGUEIREDO, NEVES VINÍCIUS. Curso de introdução ao Arduino: 2015. Universidade Federal Fluminense. Disponível em: <http://www.peteletrica.uff.br/wp-content/uploads/2015/09/Curso-deIntrodu\%C3\%A7\%C3\%A3o-ao-Arduino.pdf>. Acesso em 26 janeiro 2019.

[5] TERMISTOR. Aplicação à disciplina: EE 317 - Controle e Automação Industrial. Disponível em: <http://lusosat.org/hardware/termistor.pdf>. Acesso em 26 janeiro 2019.

[6] THE ENGINEERING PROJECTS. Introduction to Arduino Nano. A complete step by step tutorial on the Introduction to Arduino Nano. Disponível em: <https://www.theengineeringprojects.com/2018/06/introduction-to-arduino-nano.html>. Acesso em 2 março 2019.

[7] SIQUEIRA, S THIAGO. Bluetooth - Características, protocolos e funcionamento: 2006. Instituto de Computação. Universidade Estadual de Campinas.

[8] GUANGZHOU HC INFORMATION TECHNOLOGY CO.,LTD. Product Datasheet, Model: HC-06. Disponível em: <https://www.olimex.com/Products/Components/RF/BLUETOOTH-SERIAL-HC06/resources/hc06.pdf $>$. Acesso em 26 janeiro 2019.

[9] ADAFRUIT. Monochrome 0.96" 128 x 64 OLED graphic display - Product ID: 326. Disponível em: <https://www.adafruit.com/product/326>. Acesso em: 26 janeiro 2019.

[10] MANUAL TÉCNICO. Módulo de Relê 4 canais:2011. Serial Link Comunicações \& Serviços.

[11] EK.T. Mini usb $1^{\text {a }}$ lithium battery charging board charger model: tp4056. Disponível em: <http://www.ekt2.com/pdf/27_CC_BATTERY_CHARGER_USB_KIT.pdf >. Acesso em 26 janeiro 2019.

[12] PIXABAY. Disponível em: < https://pixabay.com/pt/>. Acesso em 2 março 2019.

[13] APPINVENTOR. Massachusetts Institute of Technology. 2012 - 2019. Disponível em: <http://appinventor.mit.edu/explore/>. Acesso em 3 janeiro 2018.

[14] PUBLICDOMAINVECTORS. Imagem vetorial de símbolo de fonte de corrente alternada. Disponível em: $<$ https://publicdomainvectors.org/pt/vetorial-gratis/Imagem-vetorial-de-s\%C3\%ADmbolo-de-fonte-decorrente-alternada/22536.html>. Acesso em 2 março 2019.

[15] JONNY FIVE. Arduino Nano. Disponível em: 〈http://johnny-five.io/platform-support/>. Acesso em 2 março 2019 . 
[16] IDEA LINK. Pack of 10 Resistors 330 ohm 1/4W 5\%. Disponível em:< https://idealink.net/330-ohmresistor-pack>. Acesso em 2 março 2019.

[17] PNG IMAGE. RESISTOR PNG 3. Disponível em:< https://pngimage.net/resistor-png-3/>. Acesso em 2 março 2019.

[18] OLENDER, MAX. LI YUAN ELECTRONICS OLED module. GRAB CAD. Disponível em: <https://grabcad.com/library/lm096i-128064-0-96-inch-128x64-oled-module-2>. Acesso em 18 fevereiro 2019.

[19] GALINDO, BENJAMIN. HC-06 bluetooth module. GRAB CA. Disponível em: <https://grabcad.com/library/hc-06-bluetooth-module-1>. Acesso em 18 de fevereiro 2019.

[20] ANG, EON. Arduino nano with and without the ICSP pins. GRAB CAD. Disponível em: <https://grabcad.com/library/arduino-nano-9>. Acesso em 18 de fevereiro 2019.

[21] Mauer, Alain. Arduino Glasses a HMD for Multimeter. Hackaday.io, 2016. Diponível em: <https://hackaday.io/project/12211-arduino-glasses-a-hmd-for-multimeter>. Acesso em: 2 novembro 2018.

[22] ALIBABA. 90 grau multi ângulo direito óptica retangular óculos de prisma equilátero. Disponível em: <https://portuguese.alibaba.com/product-detail/90-degree-multi-optical-right-angle-rectangular-equilateralprism-glasses-60727964527.html?spm=a2700.md_pt_PT.maylikeexp.9.274d1f947QF6hh>. Acesso em 2 março 2019. Autor 1, A.B. Título do Trabalho. Grau do Trabalho (dissertação, tese etc), Universidade, Localização da Universidade, Data de Finalização. 